\title{
Article \\ Optimization of Lyophilized Hyperacute Serum (HAS) as a Regenerative Therapeutic in Osteoarthritis
}

\author{
Isabel Olmos Calvo ${ }^{1, *(\mathbb{D})}$, Olga Kuten-Pella ${ }^{1} \mathbb{D}$, Karina Kramer ${ }^{2}$, Ágnes Madár ${ }^{1}$, Szilvia Takács ${ }^{1}$, \\ Dorottya Kardos $^{3}$ (D), Diána Simon ${ }^{4}$, Szabina Erdö-Bonyár ${ }^{4}$, Timea Berki ${ }^{4}$, Andrea De Luna ${ }^{2}$, Stefan Nehrer ${ }^{2}$ \\ and Zsombor Lacza ${ }^{5,6}$
}

check for updates

Citation: Olmos Calvo, I.; Kuten-Pella, O.; Kramer, K.; Madár,

Á.; Takács, S.; Kardos, D.; Simon, D.; Erdö-Bonyár, S.; Berki, T.; De Luna,

A.; et al. Optimization of Lyophilized Hyperacute Serum (HAS) as a Regenerative Therapeutic in Osteoarthritis. Int. J. Mol. Sci. 2021, 22, 7496. https://doi.org/10.3390/ ijms22147496

Academic Editor: Tomoyuki Kawase

Received: 11 June 2021

Accepted: 9 July 2021

Published: 13 July 2021

Publisher's Note: MDPI stays neutral with regard to jurisdictional claims in published maps and institutional affiliations.

Copyright: (c) 2021 by the authors. Licensee MDPI, Basel, Switzerland This article is an open access article distributed under the terms and conditions of the Creative Commons Attribution (CC BY) license (https:// creativecommons.org/licenses/by/ $4.0 /)$.
1 OrthoSera GmbH, Dr. Karl-Dorrek-Straße 23-29, 3500 Krems an der Donau, Austria; olga.kuten@orthosera.com (O.K.-P.); agnes.madar@orthosera.com (Á.M.); szilvia.takacs@orthosera.com (S.T.)

2 Center for Regenerative Medicine, Danube University of Krems, 3500 Krems an der Donau, Austria; karina.kramer@donau-uni.ac.at (K.K.); Andrea.DeLuna@donau-uni.ac.at (A.D.L.); stefan.nehrer@donau-uni.ac.at (S.N.)

3 Research Center for Natural Sciences, 1117 Budapest, Hungary; dorottya333@gmail.com

4 Department of Immunology and Biotechnology, Medical School, University of Pécs, 7624 Pécs, Hungary; simon.diana@pte.hu (D.S.); erdo-bonyar.szabina@pte.hu (S.E.-B.); berki.timea@pte.hu (T.B.)

5 Department of Sport Physiology, University of Physical Education, 1123 Budapest, Hungary; zsombor.lacza@orthosera.com

6 Institute of Translational Medicine, Semmelweis University, 1085 Budapest, Hungary

* Correspondence: isabel.olmos@orthosera.com

Abstract: Hyperacute serum (HAS) is a blood derivative product that promotes the proliferation of various cell types and controls inflammation in vitro. The aim of this study is to investigate the regenerative potential of different formulations of HAS, including lyophilized and hyaluronic acid combined versions, to obtain a stable and standardized therapeutic in osteoarthritis (OA), which may be able to overcome the variability limitations of platelet-rich plasma (PRP). Primary human osteoarthritic chondrocytes were used for testing cellular viability and gene expression of OA-related genes. Moreover, a co-culture of human explants of cartilage, bone and synovium under inflammatory conditions was used for investigating the inflammatory control capacities of the different therapeutics. In this study, one formulation of lyophilized HAS achieved the high cell viability rates of liquid HAS and PRP. Gene expression analysis showed that HAS induced higher Col1a1 expression than PRP. Cytokine quantification from supernatant fluids revealed that HAS treatment of inflamed co-cultures significantly reduced levels of IL-5, IL-15, IL-2, TNF $\alpha$, IL-7 and IL-12. To conclude, lyophilized HAS is a stable and standardized therapeutic with high potential in joint regeneration.

Keywords: hyperacute serum; osteoarthritis; joint regeneration; explant co-culture; blood derived product; inflammatory cytokines; bone remodeling

\section{Introduction}

Osteoarthritis (OA) is the most common joint degenerative disease, especially affecting the elderly population, which it is expected to increase in the next decades [1]. OA is characterized by articular cartilage and subchondral bone destruction leading to locomotor disability and pain. The lack of an effective current treatment to regenerate or impede joint destruction in the context of OA has left alleviating symptoms as the only therapeutic option until the joint is surgically replaced [2].

Different blood derivate products obtained after whole blood centrifugation has become a novel and attractive therapy [3]. The aim is to isolate and concentrate specific components that may have a potential effect in the context of tissue engineering. Different preparation processes lead to different compositions and therefore, different potential outcomes in modulating cell proliferation and inflammation [4]. These blood derivative 
products are then intraarticularly injected into osteoarthritic joints. Particularly, plateletrich plasma (PRP) has become the therapeutic mostly used for this purpose [5]. However, there are multiple studies that have shown controversy about its benefits and it may not be the optimal solution to stop or reverse the degenerative process in the joints [6-8]. The main disadvantage relates to its composition variability due to different production techniques and its relevant content of pro-inflammatory agents such as fibrin and leukocytes [9-13].

In contrast, hyperacute serum (HAS) is a cell and fibrin-free solution, obtained after pressing out fibrin clots, which maintains the highly regenerative capacities of PRP. Previous studies of HAS used the freshly isolated formulation, a liquid version, which proved to induce cell proliferation of chondrocytes, bone marrow mesenchymal stem cells, osteoblasts in cell culture and in a bone ischemic model [14-18]. Kardos et al. established a more complex biological model consisting of a human explant co-culture of bone, articular cartilage and synovium, which was used to study the effect of HAS under inflammatory conditions showing that HAS reduced inflammation as well as induced cell proliferation [19]. This human explant model allows communication between tissues, better representing the damage caused during OA within the joint, which experimentally is sometimes simplified to cartilage or bone in vitro cultures. It is known that $\mathrm{OA}$ also causes synovitis, effusion of synovial fluid, osteophyte formation and muscle weakness and atrophy, therefore supporting the use of more complex models [20-22]. In fact, synovial fluid has been used to identify and quantify possible biomarkers of OA, including the proinflammatory interleukins IL-6, IL-1 $\beta$ and tumor necrosis factor alpha (TNF $\alpha)$; however, the complexity and high amount of proteins involved in OA, together with the variability between patients has not so far allowed to reach a clear conclusion about this issue [23-26]. Still, inflammation during OA has been shown to have an impact on extracellular matrix (ECM) composition, perpetuating the pathology [27].

Freshly isolated HAS enables autologous therapy but has limitations during clinical administration. In order to produce a stable and standardized product that allows for long storage periods, HAS in freeze dried format has been produced and tested. During the lyophilization process, sublimation of the contained frozen water and the subsequent separation of vapor produces a powder-in our case, HAS powder [28,29]. Lyophilization may allow to use the product in an allogenic way; the idea is to produce it by pooling the serum from fibrin clots of multiple healthy and young donors, reducing variability between batches, and providing a nutrient-enriched formulation. For this purpose, two versions of lyophilized HAS were produced: the first one with an extra immunoglobulin M (IgM) filtration step, referred to as "filtered lyophilized HAS"; and a second one without the mentioned step, "non-filtered lyophilized HAS". Moreover, visco-supplementation of hyaluronic acid (HA) has been widely used as a treatment of OA due to its mechanical properties and its demonstrated capacity for reducing local inflammation $[7,30]$. The combination of HA with a therapeutic that may induce a synergistic positive biological effect has gained interest in the last years [31-33]. The aim of this study was to test if lyophilized HAS reaches the regenerative potential of other blood derivative products for OA treatment alone and in combination with HA.

\section{Results}

\subsection{Optimizing HAS Production Based on Chondrogenic Viability Effect}

Two concentrations of filtered lyophilized HAS were compared to the known gold standard supplementation, fetal calf serum (FCS) (Figure 1A). Statistical time-dependent analysis showed a significant increase in cell viability over time after supplementation with $10 \%$ FCS and 20\% filtered lyophilized HAS ( $p=0.0298, p=0.0375$, respectively). When linear regressions of the three groups were compared, no significant differences between the groups were found. This data suggests that in vitro chondrocyte viability after filtered lyophilized HAS supplementation reaches an FCS-induced effect. Moreover, doubling the concentration of lyophilized HAS to $20 \%$ of the total volume did not increase chondrocyte viability. Then, filtered lyophilized HAS was compared to freshly isolated HAS and PRP 
(Figure 1B). Freshly isolated HAS and PRP significantly increased chondrocyte viability over time ( $p=0.029$ and $p=0.002$, respectively) and their linear regression comparison showed no statistical difference. However, filtered lyophilized HAS did not support chondrocyte viability as strongly as freshly isolated HAS and PRP ( $p=0.0047$ and $p$-value not possible to calculate due to the high difference of the linear slopes, respectively). The potential removal of nutrient supply within filtered lyophilized HAS, due to the IgM filtration step, led us to produce a new version of lyophilized HAS which excluded the already mentioned filtration step. The same experiment was repeated with this new HAS formulation, demonstrating that non-filtered lyophilized HAS increased chondrocyte viability over time $(p=0.0445)$. Linear regression comparisons between non-filtered lyophilized and freshly isolated HAS revealed no statistical difference (Figure 1C). In contrast, same comparison showed that non-filtered lyophilized HAS significantly promoted cell viability when compared to the filtered version of HAS ( $p=0.0075)$. This data suggests that non-filtered HAS achieves the outstanding supplementation levels of the freshly isolated formulation, with the advantages of being a lyophilized powder.

A
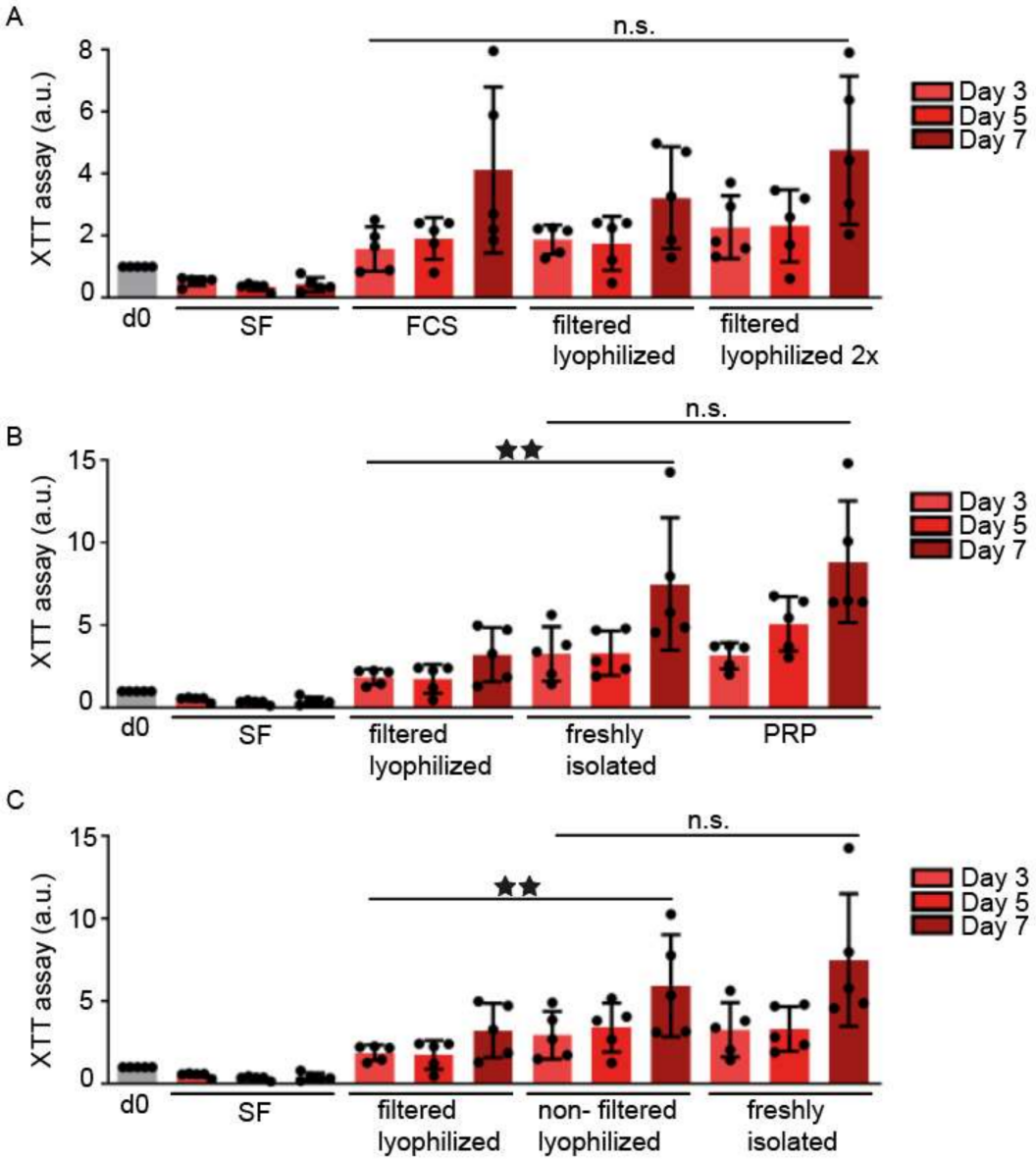

Figure 1. Chondrocyte viability by XTT assay over time (days 3, 5 and 7). Comparisons include (A) two concentrations (10\% and $20 \%$ ) of filtered lyophilized HAS (represented as filtered lyophilized and filtered lyophilized $2 \times$, respectively) and 10\% FCS; (B) filtered lyophilized HAS, freshly isolated HAS and PRP; (C) the two versions of lyophilized (filtered and non-filtered) and freshly isolated HAS. Serum free $(\mathrm{SF})$ and day $0(\mathrm{~d} 0)$ were used as negative controls in all experiments $(\mathrm{n}=5)$. Bars represent arithmetic means and error bars show standard deviations (SD). Other abbreviations: not significant (n.s.), arbitrary units (a.u.), fetal calf serum (FCS), level of significance where $p<0.01{ }^{* *}$ ).

To investigate a possible synergistic effect between HA and HAS, HA was supplemented to the filtered and non-filtered lyophilized HAS formulations. Cell viability measurements via XTT assay showed no statistical significance (Table 1). 
Table 1. Chondrogenic viability after supplementation with hyperacute sera with and without HA.

\begin{tabular}{ccccccc}
\hline & \multicolumn{7}{c}{ HA } \\
\hline & - & + & - & + & - & + \\
\hline FCS & 1.5722 & 2.1943 & 1.9111 & 1.6714 & 4.1204 & 3.8288 \\
\hline Filtered lyophilized HAS & 1.8737 & 1.8371 & 1.9618 & 1.0740 & 3.2265 & 3.8791 \\
\hline Non-filtered lyo. HAS & 2.9374 & 3.3930 & 3.2409 & 3.3741 & 5.8379 & 7.0123 \\
\hline & \multicolumn{2}{c}{ Day 3 } & \multicolumn{2}{c}{ Day 5 } & \multicolumn{2}{c}{ Day 7 }
\end{tabular}

Mean chondrocyte viability measured by XTT assay at days 3,5 and 7, comparing filtered and non-filtered lyophilized HAS in the presence or absence of HA. Data represents fold change (in a.u.) normalized to the "d0" condition $(\mathrm{n}=5)$.

\subsection{Gene Expression of Osteoarthritis-Related Genes after Blood Derivatives Supplementation}

Gene expression analysis showed that genes related to ECM formation such as collagen type I alpha 1 chain (Col1a1), collagen type II alpha 1 chain (Col2a1) and aggrecan (Acan) were upregulated after supplementation with the different HAS formulations when compared to PRP (Figure 2A-C). However, only PRP expression for Col1a1 was significantly lower when compared to non-filtered lyophilized and freshly isolated HAS ( $p=0.04$ and $p=0.034$, respectively). Statistical tests from Col2a1 and Acan data did not reach statistical significance, probably due to donor variability. Col2a1 expression decreased for all conditions when compared to day 0, similarly to the SRY-Box transcription factor 9 (Sox9) expression (Figure 2B,G). Metalloproteinases Mmp-3, Mmp-13 and lubricin (Prg4) expression showed high variability between patients; consequently, no conclusive outcome could be defined (Figure 2D-F).

A

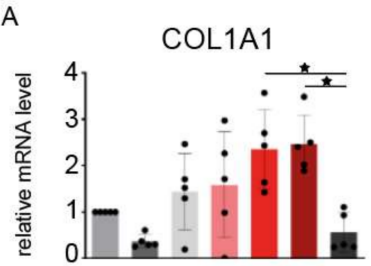

D

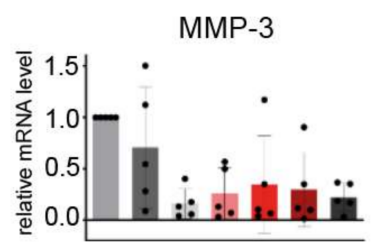

G

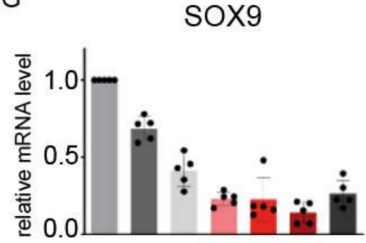

B

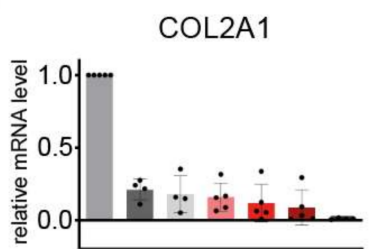

$\mathrm{E}$

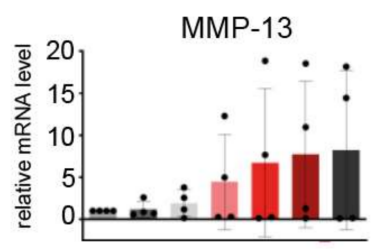

C

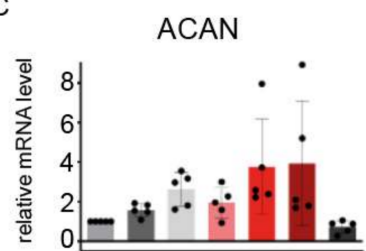

F

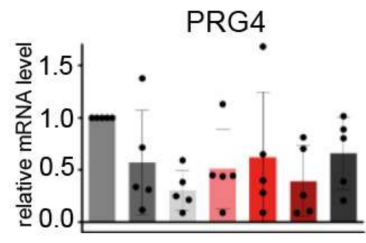

Figure 2. Gene expression of OA-related genes from a chondrogenic 2D culture after supplementation with different versions of HAS and PRP ( $\mathrm{n}=5)$. Tested genes include (A) Col1a1, (B) Col2a1, (C) Acan, (D) Mmp-3, (E) Mmp-13, (F) Prg4, and (G) Sox9. Bars represent arithmetic means and error bars, SD. Abbreviations: day 0 (d0), serum free (SF), fetal calf serum (FCS), hyperacute serum (HAS), platelet-rich plasma (PRP), collagen type I alpha 1 chain (COL1A1), collagen type II alpha 1 chain (COL2A1), aggrecan (ACAN), metalloproteinases (MMP), proteoglycan 4/lubricin (PRG4) and SRY-box transcription factor 9 (SOX9). Level of significance where $p<0.05\left(^{*}\right)$. 
The same gene expression analysis was performed on the samples where HAS was combined to HA (Table 2). The results showed no significant difference for any tested gene.

Table 2. Gene expression of OA-related genes after supplementation with HAS and HA.

\begin{tabular}{ccccccc}
\hline & \multicolumn{2}{c}{ FCS } & \multicolumn{2}{c}{ Filtered Lyophilized } & \multicolumn{2}{c}{ Non-Filtered Lyophilized } \\
\hline Genes & - & + & - & + & - & + \\
\hline Col1a1 & $1.43( \pm 0.82)$ & $1.76( \pm 0.60)$ & $1.55( \pm 1.14)$ & $2.27( \pm 1.21)$ & $2.32( \pm 0.86)$ & $2.45( \pm 0.74)$ \\
\hline Col2a1 & $0.17( \pm 0.12)$ & $0.25( \pm 0.12)$ & $0.15( \pm 0.09)$ & $0.13( \pm 0.12)$ & $0.11( \pm 0.12)$ & $0.12( \pm 0.09)$ \\
\hline Acan & $2.61( \pm 0.86)$ & $2.70( \pm 0.65)$ & $1.94( \pm 0.76)$ & $2.63( \pm 0.77)$ & $3.77( \pm 2.41)$ & $4.67( \pm 1.98)$ \\
\hline Mmp-3 & $0.16( \pm 0.14)$ & $0.28( \pm 0.26)$ & $0.25( \pm 0.25)$ & $0.33( \pm 0.37)$ & $0.34( \pm 0.47)$ & $0.31( \pm 0.32)$ \\
\hline Mmp-13 & $1.91( \pm 1.59)$ & $1.68( \pm 1.69)$ & $4.44( \pm 5.67)$ & $3.62( \pm 4.31)$ & $6.72( \pm 8.82)$ & $8.85( \pm 13.76)$ \\
\hline Prg4 & $0.30( \pm 0.19)$ & $0.30( \pm 0.23)$ & $0.50( \pm 0.37)$ & $0.49( \pm 0.44)$ & $0.62( \pm 0.62)$ & $0.38( \pm 0.32)$ \\
\hline Sox9 & $0.43( \pm 0.10)$ & $0.38( \pm 0.08)$ & $0.23( \pm 0.04)$ & $0.26( \pm 0.05)$ & $0.22( \pm 0.14)$ & $0.17( \pm 0.07)$ \\
\hline
\end{tabular}

Mean mRNA gene expression $( \pm \mathrm{SD})$ of OA-related genes from a chondrogenic 2D culture after supplementation with filtered and non-filtered lyophilized HAS in the presence or absence of HA $(n=5)$.

\subsection{Protein Profiling after Treating the Inflamed Explant Co-Culture Model with HAS}

Human fragments of bone, articular cartilage and synovial tissues were used to establish a co-culture mimicking inter-tissue communication located at the joints (Figure 3A-D). After 2 days under IL- $1 \beta$ stimulation and a subsequent period of 5 days in the presence of nonfiltered HAS and/or HA, XTT viability tests were performed. A one-way ANOVA test showed no significant difference between the groups in all tissues (Figure $3 \mathrm{E}-\mathrm{G}$ ).

A

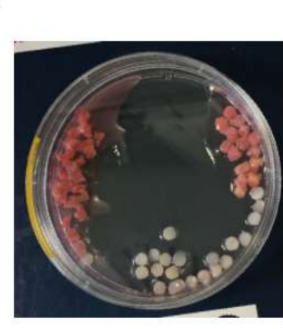

E
B

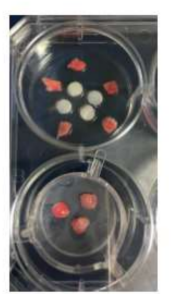

C

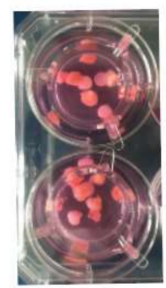

D

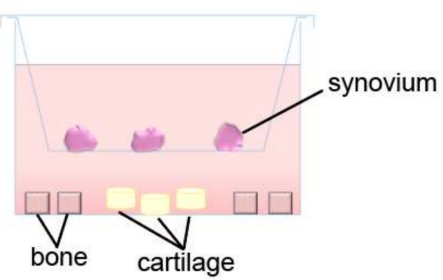
$\mathrm{F}$ G Cartilage Synovium
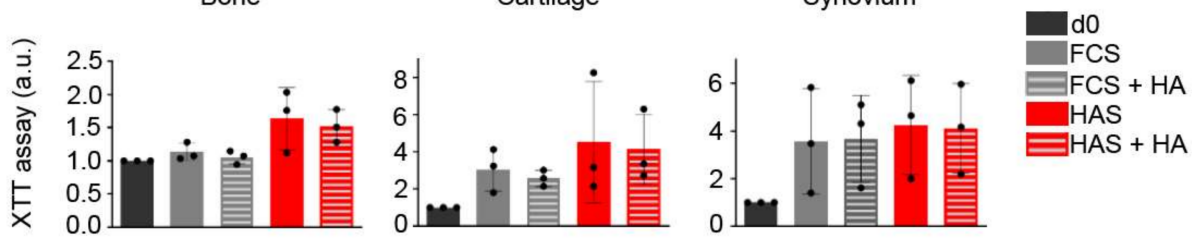

Figure 3. Establishment of an inflammatory ex vivo joint model. (A) Bone, cartilage, and synovium fragments from human samples of patients undergoing knee replacement were minced and transferred to cultured wells. (B,C) In each well, five fragments of bone, four of cartilage and two or three of synovium were placed as shown in the images and (D) in the side view scheme. XTT viability assay after a total of 7 days of culture was performed for (E) bone, (F) cartilage and (G) synovium. Bars represents arithmetic mean values $\pm \mathrm{SD}(\mathrm{n}=3)$. Abbreviations: day $0(\mathrm{~d} 0)$, serum free (SF), fetal calf serum (FCS), hyperacute serum (HAS), platelet-rich plasma (PRP), hyaluronic acid (HA), arbitrary units (a.u.).

At the same time point, supernatant fluids were collected, and cytokines and growth factors were quantified (Figure 4). When compared to FCS, HAS supplementation induced a significant decrease of the pro-inflammatory cytokines IL-5 ( $p=0.021)$, IL-15 ( $p=0.045)$, 
TNF $\alpha(p=0.038)$, IL-2 $(p=0.034)$, IL-7 $(p=0.031)$ and IL-12 $(p=0.048)$; and the growth factor GM-CSF $(p=0.045)$. HA induced a significant reduction of MIP-1 $\beta$ expression when compared to FCS alone $(p=0.045)$. The combination of HAS and HA only maintained the significantly different expression for IL-5 $(p=0.021)$.

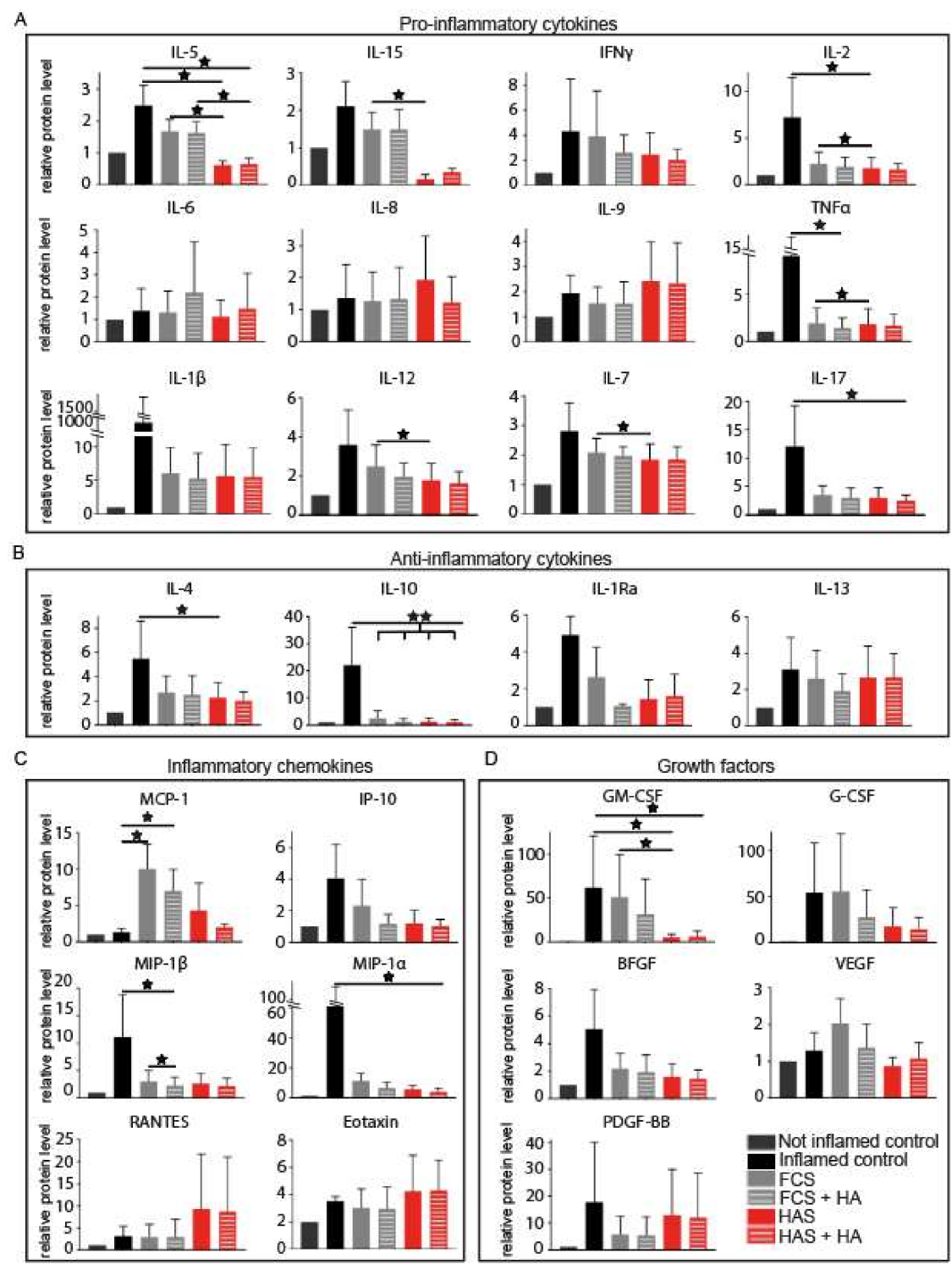

Figure 4. Quantification of cytokines and growth factors from supernatant fluids after 5 days of treatment with HAS and/or HA of a previously inflamed explant human co-culture. Proteins were grouped as (A) pro-inflammatory cytokines, (B) anti-inflammatory cytokines, (C) inflammatory chemokines and (D) growth factors. Inflamed (positive) control correspond to samples exposed to inflammation, before any treatment was added at day 0 . Not inflamed (negative) control represent samples that were not exposed to inflammatory conditions before day 0 . Bars represent arithmetic mean values $\pm S D(n=3)$. Abbreviations: fetal calf serum (FCS), hyperacute serum (HAS), hyaluronic acid (HA), interleukins (IL-), tumor necrosis factor alpha (TNF $\alpha$ ), interferon gamma (IFN $\gamma$ ), interleukin 1 receptor antagonist (IL-1Ra), monocyte chemotactic protein 1 (MCP-1), $10 \mathrm{KDa}$ interferon gamma-induced protein (IP-10), macrophage inflammatory proteins (MIP), regulated upon activation normally T-expressed and presumably secreted (RANTES), granulocyte macrophage colony stimulating factor (GM-CSF), granulocyte colony stimulating factor (G-CSF), vascular endothelial growth factor (VEGF), basic fibroblast growth factor (BFGF) and platelet-derived growth factor subunit $\mathrm{B}$ (PDGF-BB). Level of significance where $p<0.05\left(^{*}\right)$ and $p<0.01\left(^{* *}\right)$. 
Moreover, the presence of multiple proteins including IL-2, TNF $\alpha$, IL-17, IL-1 $\beta$, IL-15, IL-7, IL-12, IL-5, IL-4, IL-10, IL-1Ra, IP-10, MIP-1 $\beta$, MIP- $1 \alpha$ and BFGF decreased in all groups when the inflammatory stimuli was removed; however, only, IL-10 decreased significantly for all conditions $(p=0.009)$. When compared to the positive control, HAS reduced the amount of IL-4, IL-5, GM-CSF and IL-2 found in the supernatant fluids $(p=0.039, p=0.018, p=0.018$ and $p=0.036$, respectively); HA reduced TNF $\alpha(p=0.039)$ and MIP-1 $\beta(p=0.018)$; HAS and HA combined influenced IL-17 ( $p=0.039)$, IL-5 $(p=0.024)$, GM-CSF ( $p=0.039)$ and MIP- $1 \alpha(p=0.039)$. Interestingly, after removing the inflammatory stimulation, MCP-1 increased for the conditions containing FCS alone and in combination with HA ( $p=0.018$ and $p=0.039$, respectively), but not for the ones containing HAS HAS supplementation with and without HA showed a non-significant trend in increasing the levels of RANTES and Eotaxin. All $p$-values are listed in Supplementary Materials (Table S1).

Correlations of protein changes after supplementation of the four conditions: FCS or HAS \pm HA ((day 0, inflamed control)—(day 5, treatment)) were calculated. Pearson's correlations were very strong between the groups where HA was added, and their controls: FCS or HAS alone $(r=0.988$ and $r=0.984$, respectively). However, the correlation between HAS and FCS was weaker $(r=0.649)$, suggesting a more different cytokine and growth factor profile. Individual gene expressions were analyzed, correlated, and plotted as heatmaps for FCS (Figure 5A), FCS+HA (Figure 5B), HAS (Figure 5C) and HAS+HA (Figure 5D). Values for each correlation can be found in Supplementary Table S2 (Table S2). When analyzing individual genes, the FCS-supplemented group strongly correlated genes gathered as follows: PDGF-BB, IL-12, MIP-1 $\beta$, IL1-Ra and IL-6; GM-CSF, RANTES, IL-2, IL9, IL-10, G-CSF, IP-10 and IL-13; VEGF, IL-7, IFN $\gamma$, IL-8, and IL-1 $\beta$; MIP-1 $\alpha$, IL-15, MCP-1 and BFGF. This last subgroup correlated negatively to the two first clusters listed. Lastly, the strongly correlated cluster IL-5, IL-4, IL-17, TNF $\alpha$ and Eotaxin negatively correlated to most of the genes grouped in the second cluster. The group treated with HAS showed that strongly correlated genes tended to form smaller clusters, leading to less complex negative correlations. For example, the cluster MIP-1 $\beta$, IL-1Ra, IL-7 and IL-6 negatively correlated to the subgroups Eotaxin, IL-5, and MCP-1; VEGF and IL-8; and IL-4, IL-15 and IL-17. The strongly correlated subgroup formed by GM-CSF, IL-10, G-CSF, RANTES, IL-9, IL-2, MIP- $1 \alpha$ and IL-12 negatively correlated to the clusters TNF $\alpha$, IFN $\gamma$ and IL- $1 \beta$; and Eotaxin, IL-5, MCP-1, VEGF and IL-8.

To better understand differences between HAS and FCS-supplemented cultures, and the possible synergistic effect of HA to HAS, proteins were divided into two blocks depending on their positive or negative correlations (Figure 5E). This approach showed that although interactions between cytokines and growth factors may be different between the treated groups, most of them remained on their side of the correlation, with a few exceptions listed in Table 3. When a treatment was added to the culture after inflammation (HA, HAS or the combination of both) MIP- $1 \alpha$, VEGF, IFN $\gamma$, IL- 8 and IL- $1 \beta$ behaved differently. HAS supplementation induced changes in BFGF, and HA promoted changes in IL-2, IL-7, IL-13 and IL-12 that were maintained during HAS + HA treatment. Moreover, there were some proteins that positively correlated to both sides of the correlation, acting as switching factors: IL-1 $\beta$ for FCS condition, IL-2 for HA, and IP-10 and IL-2 for HAS + HA treatment (Figure 5E). 


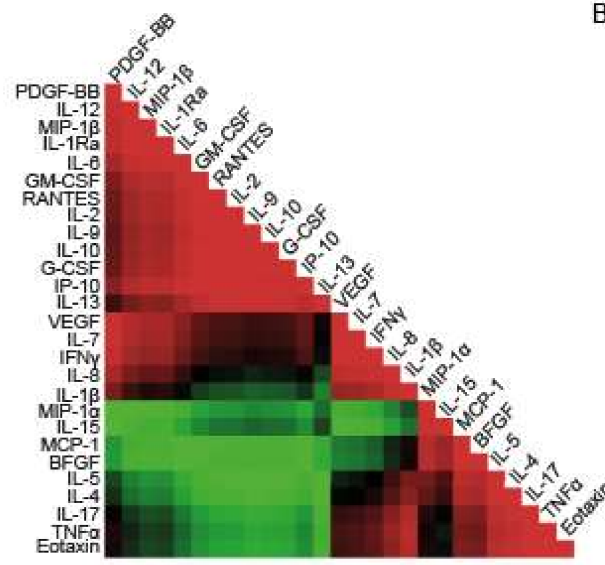

C

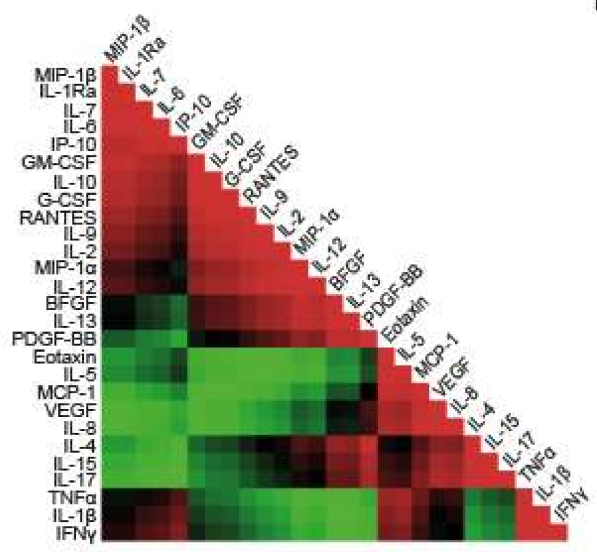

E
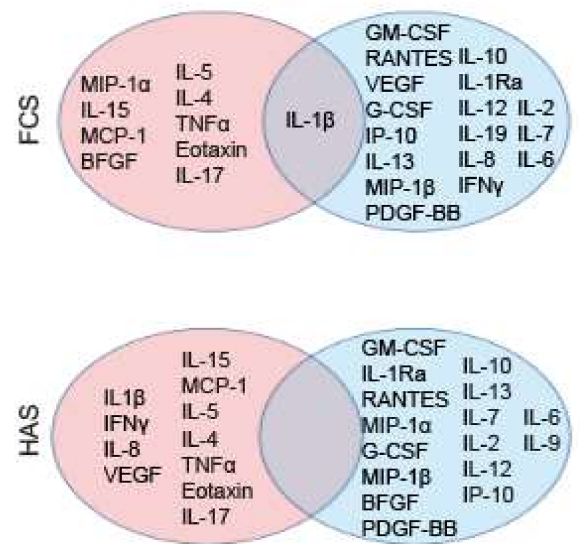

B

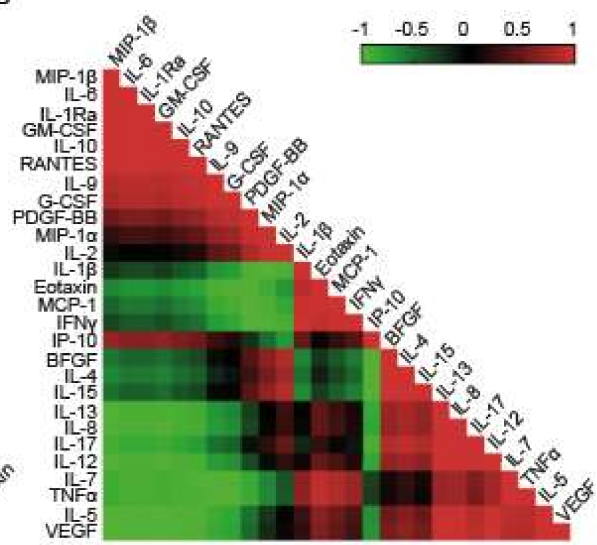

D
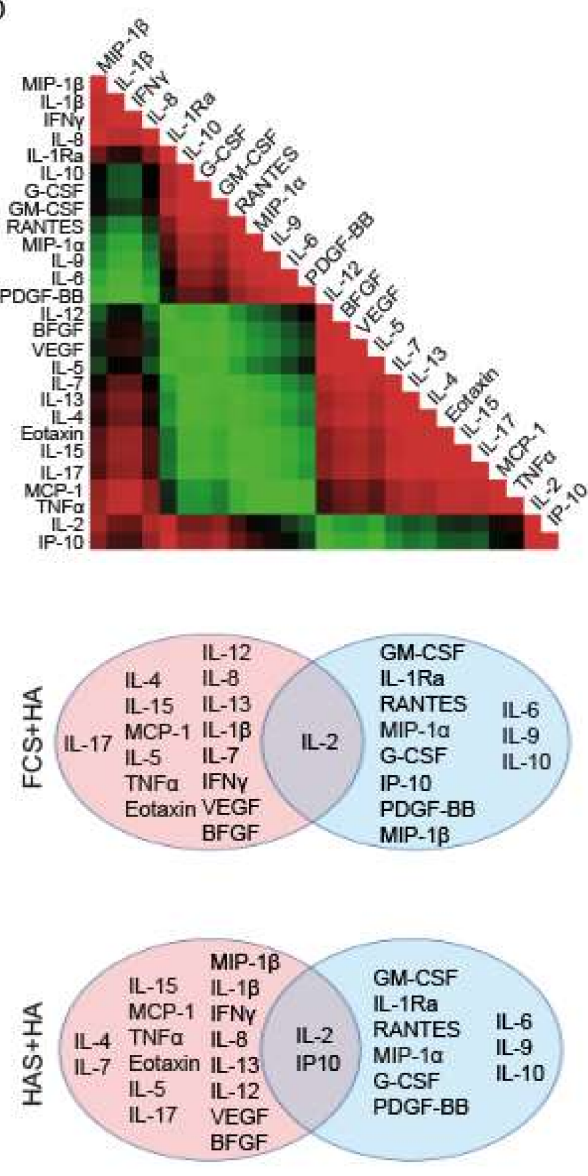

Figure 5. Correlations of cytokines and growth factor changes visualized as heatmaps for all conditions: (A) FCS, (B) FCS + HA, (C) HAS and (D) HAS + HA. Red color represents values close to 1 of the Pearson's correlation, suggesting positive correlation patterns. Green color represents values for the Pearson's correlation close to -1 , indicating negative correlations. Black color means no direct correlation between the genes. (E) Scheme of genes manually separated according to their correlations into two blocks that negatively correlate between them. There is no color code meaning. $(\mathrm{N}=3)$. Abbreviations: fetal calf serum (FCS), hyperacute serum (HAS), hyaluronic acid (HA), interleukins (IL-), tumor necrosis factor alpha (TNF $\alpha)$, interferon gamma (IFN $\gamma)$, interleukin 1 receptor antagonist (IL-1Ra), monocyte chemotactic protein 1 (MCP-1), $10 \mathrm{KDa}$ interferon gamma-induced protein (IP-10), macrophage inflammatory proteins (MIP), regulated upon activation normally T-expressed and presumably secreted (RANTES), granulocyte macrophage colony stimulating factor (GM-CSF), granulocyte colony stimulating factor (G-CSF), vascular endothelial growth factor (VEGF), basic fibroblast growth factor (BFGF) and platelet-derived growth factor subunit B (PDGF-BB). 
Table 3. List of genes with a differential correlation pattern after treatment supplementation.

\begin{tabular}{cc}
\hline Treatment Conditions & Genes \\
\hline+ HAS $/+$ HA $/+$ HAS and + HA & MIP-1 $\alpha$, VEGF, IFN $\gamma$, IL-8, IL-1 $\beta$ \\
\hline+ HA & IL-2, IL-7, IL-13, IL-12 \\
\hline+ HAS & BFGF \\
\hline +HAS and +HA & IL-2, IL-7, IP-10, IL-12, IL-13, MIP-1 $\beta$ \\
\hline
\end{tabular}

\section{Discussion}

This study focuses on the optimization of HAS formulation development, in a way that can ensure scale-up manufacturing as well as the maintenance of the quality of the therapeutic product. For this purpose, primary chondrocytes were kept in culture under different supplementation conditions, including three versions of HAS: one liquid format, also referred in this manuscript as "freshly isolated", and two lyophilized versions, one of them with an extra IgM filtration step. Moreover, PRP, FCS and combinations of the different HAS formulations in the presence of HA were also compared. It is widely known that lyophilization, or freeze-drying, of sterile therapeutics extends the long-term stability of molecules, including large molecules such as proteins $[34,35]$. For this reason, lyophilization is currently involved in the manufacturing process of $50 \%$ of the total biopharmaceutical products $[36,37]$. Blood-derived products are usually used in an autologous liquid format and lyophilization may ease the standardization of such products [9].

HAS is being tested as a possible therapeutic of OA with the aim of preventing joint degeneration. Previous studies showed that freshly isolated HAS more significantly induced cell proliferation of mesenchymal stromal cells, chondrocytes and in bone explants than PRP supplementation [15-18]. Moreover, Vacz et al. demonstrated that in ischemia conditions, freshly isolated HAS significantly increased cell proliferation within bone fragments when compared to PRP [14]. Interestingly, previous studies had already shown that PRP increase chondrogenic in vitro proliferation [38-40], suggesting that HAS may be a better alternative to induce chondrogenic proliferation when compared to PRP. In this study, a first version of lyophilized HAS, so-called "filtered lyophilized HAS", did not reach the high supplementation standards of the freshly isolated HAS version and PRP in 2D cultured chondrocytes. We hypothesized that due to the already mentioned extra filtration step during manufacturing, important components involved in promoting cell viability were removed. Therefore, the IgM filtration step was skipped and a new lyophilized HAS, referred as "non-filtered lyophilized HAS", was produced, which equaled cell viability rates obtained with the freshly isolated formulation. It has been shown that PRP formulations release multiple cytokines in high concentrations, including PDGF-AB, PDGF-BB, transforming growth factor $\beta$ (TGF- $\beta$ ), VEGF, insulin-like growth factor-1 (IGF-1) and epidermal growth factor (EGF) [3]. Growth factors and protein content of freshly isolated HAS have been analyzed and quantified in previous studies $[4,14]$. Kuten et al. showed that the in vitro effect of freshly isolated HAS was more predictable and reliable than PRP, probably due to its growth factor profile and the absence of the anticoagulants needed during PRP production. Except IGF-1 release, which had a comparable release from HAS and PRP; VEGF, TGF- $\beta$ and PDGF presence after HAS supplementation was moderate when compared to PRP [15]. These data support the findings from this study concerning the quantification of VEGF, PDGF-BB and BGFG.

Genes related to joint degeneration and ECM production were quantified. Col1a1 and Acan expressions were increased after supplementation with different formulations of HAS; however, these comparisons were only statistically significant when compared to PRP for Col1a1, as previously observed elsewhere [16,17]. Interestingly, Sox 9 and Col2a1 expression decreased in all conditions after 5 days in culture, which may suggest that cells started to lose the chondrogenic phenotype, as shown in other study where different culture media were used [15]. Results for Mmp-3, Mmp-13 and Prg4 expression were inconclusive due to 
the high variability between the donors. In this study, we have not observed a synergistic effect on chondrogenic viability or gene expression of OA-related genes when HAS was supplemented with HA. Contradictory results about similar studies using a combination of PRP and HA can be found in the literature, probably due to the multiple PRP formulations available and the multitude of commercial HA possibilities [33,41-43]. Therefore, there is a need for continuing the investigation of the possible synergistic effect of HA and HAS, possibly under mechanical stimulation or in vivo, that are closer to the clinical setting.

In order to better mimic the in vivo OA pathogenesis and to test if non-filtered lyophilized HAS may have a clinical application for it, 3D human explant co-cultures consisting on fragments of bone, articular cartilage and synovium were established and exposed to IL- $1 \beta$ as previously described [19]. It is well known that injured knee joint components can contribute to changes in other joint tissues; this supports the use of in vitro co-culture systems [44,45]. IL-1 $\beta$ is one of the main pro-inflammatory cytokines that plays a role in the pathogenesis of OA; therefore, it is commonly used in vitro for mimicking an OA-diseased state [46-48]. Two days after administration of IL- $1 \beta$, levels of pro-inflammatory cytokines including TNF $\alpha$, IL-17, IL-2, IL-5 and IL-15; chemokines such as MIP- $1 \alpha$, MIP-1 $\beta$ and IP-10; and the anti-inflammatory cytokines IL-4, IL-10, IL-1Ra and IL-13 increased. As expected, when IL-1 $\beta$-containing medium was removed, the inflammatory cascade generally diminished. Strikingly, after the therapeutic culture phase, FCS and FCS + HA conditions, but not HAS, induced higher levels of MCP-1, which is a chemoattractant for monocytes and basophils that has been associated with OA [49]. Cell viabilities from the treated tissues were analyzed, and although there was a tendency in the upregulation of cell viability after supplementation with HAS in bone, the level of significance was not reached. However, Kardos et al. demonstrated in a similar experiment with a higher sample size that cell viability was significantly promoted in bone, cartilage and synovium after 5 days of culture in the presence of freshly isolated HAS when compared to FCS [19]. The presence of HA did not alter cell viability of FCS or HAS-supplemented groups.

Cytokine profiling after treating the inflamed co-cultures with HAS showed a significant decrease of IL-5, IL-15, IL-2, TNF $\alpha$, IL-7, IL-12 and GM-CSF when compared to FCS. It has been shown that IL-2, IL-12, IL-15, IL-7 and TNF $\alpha$ are upregulated during OA $[50,51]$. Moreover, the inhibition of GM-CSF revealed pain relief and prevented the development of OA in mice [52], and is therefore a potential target for the treatment of OA and rheumatoid arthritis [53]. Therefore, HAS may be a potential therapeutic to control the inflammation caused during OA. Interestingly, IL-5 is not commonly linked to OA, as its main functions relate to maturation, recruitment and survival of eosinophils. However, a recent study has found that eosinophils abundance is significantly higher at the synovium of OA patients [54]. Moreover, is IL-5 located in the same gene cluster as GM-CSF and IL-4, in chromosome 5q31, which may explain a similar behavior of the cytokines after HAS treatment. In this study, we have also observed that HA-treated co-cultures influenced MIP1- $\beta$ expression, which, together with IL-2, IL-5 and MCP-1 has been also related severe OA [49]. However, the combination of HAS and HA only reduced the levels of IL-5, suggesting that HAS alone may be more efficient as a treatment for OA; in particular, for the severe stages of the disease. A previous study showed that freshly isolated HAS not only reduced TNF $\alpha$ and IL-12 levels from an explant co-culture, but also IL-1 $\beta$, IL-6Ra and RANKL. Moreover, it increased MMP-1, MMP-2, MMP-9, COL1A1 and osteonectin, suggesting the activation of tissue remodeling mechanisms [19].

Although some of the cytokines and growth factors were not significantly up- or down-regulated, correlations between cytokines were performed. Subgroups after HAS treatment included TNF $\alpha$, IL-1 $\beta$ and IFN $\gamma$, which negative correlated to IL-12 and MIP- $1 \alpha$. The subgroup IL-15, IL-17 and IL-4 was negatively correlated to the cohort containing IL-6, IL-1Ra MIP-1 $\beta$, IL-7 and IP-10, which, interestingly, has been shown to be a marker for different infections including malaria and dengue fever $[55,56]$. Finally, the strongly correlated subgroup IL-5, VEGF, MCP-1, IL-8 and the eosinophil chemotactic protein eotaxin was negatively correlated to the cluster formed by IL-2, IL-12, MIP-1 $\alpha$ and IL-13, 
and the first listed cluster. It has been published that the cluster of proteins eotaxin, MCP-1 and VEGF may act as an indicator for osteoarthritic knees; however, MCP-1, VEGF and IL-8 may be a marker for osteoarthritic hips [57]. Moreover, there is evidence that high levels of both IL-12 and IL-13 are related to higher osteoarthritic pain and disability [58].

The focus of this study was to develop a standardized HAS product in lyophilized format that reaches the regenerative potential of the previous freshly isolation HAS version and the widely used PRP. The high amount of therapeutics tested in this study restricted most of the experiments conducted to a sample size of 5, which in some cases limited the statistical conclusions where a trend may be observable. Moreover, the HA and HAS synergistic effect could not be proven with the tests performed; further analysis including mechanical stress may be more revealing. It could also be of interest to include more knee joint tissues into our inflammatory co-culture explant model, such as the meniscus, ligaments and infrapatellar fat pad, as well as to study HAS in vivo paracrine effects. To conclude, HAS production has been optimized to obtain a lyophilized formulation that strongly promotes cell viability and has the potential to modulate inflammatory conditions; therefore, it may be a possible therapeutic for $\mathrm{OA}$ and joint degeneration.

\section{Materials and Methods}

\subsection{Primary Osteoarthritic (OA) Chondrocytes Isolation}

Human samples from OA patients undergoing complete or partial joint replacement were collected after obtaining a study approval by the Ethics Committee from NiederOesterreich (GS4-EK-4/674-2020) on the 17 November 2020, and prior obtaining a signed informed consent from the patients. Primary chondrocytes were isolated from the remaining articular cartilage of the samples by mincing the cartilage and incubating it for $16 \mathrm{~h}$ at $37^{\circ} \mathrm{C}$ in serum-free DMEM/F12 GlutaMAX medium (Gibco, 31331093) in the presence of 2 WU liberase (Roche Diagnostics, 5401119001) per gram of cartilage. After the incubation, cell suspension was strained through a $40 \mu \mathrm{m}$ cell strainer (Corning, 431750), chondrocytes were counted and seeded in culturing DMEM medium supplemented with $10 \%$ fetal calf serum (Gibco, 10500064), 200 U/mL Penicillin-0.2 mg/mL Streptomycin (Sigma-Aldrich Chemie GmbH, P4333-100 mL), $2.5 \mu \mathrm{g} / \mathrm{mL}$ Amphotericin B (Sigma-Aldrich Chemie GmbH, A2942-100 mL), and $0.05 \mathrm{mg} / \mathrm{mL}$ ascorbic acid (Sigma-Aldrich Chemie GmbH, A5960-25 g). Medium was exchanged weekly during cellular expansion and cells were used when $80 \%$ of confluency was reached.

\subsection{Preparation of PRP}

Whole blood donations from healthy human volunteers between 25 and 45 years old were used to prepare PRP. The exclusion criteria of donors included pregnancy, underweight or diabetes. Whole blood was collected following standards for blood collection and screened for infections. Whole blood was transferred into a citrate-coated tube (VACUETTE 9NC trisodiumcitrate 3.2\%, Greiner BioOne, Cat No. 455322) and centrifuged at $440 \times g$ at room temperature for $10 \mathrm{~min}$. The top fraction, containing the platelets, was transferred to a new tube, and centrifuged again at $1710 \times g$ at room temperature for $10 \mathrm{~min}$. The platelet pellet was resuspended within one third of the supernatant plasma. PRP from different donors were pooled and stored at $-20^{\circ} \mathrm{C}$.

\subsection{Preparation of Hyperacute Serum (HAS)}

Freshly isolated HAS was obtained from whole blood donations from healthy human volunteers, following the already mentioned guidelines. Whole blood was transferred to the HAS Inject Device (OrthoSera) and centrifuged at $1710 \times g$ at room temperature for $10 \mathrm{~min}$. After centrifugation, the serum and the clot containing red blood cells were discarded. The fibrin clot was isolated and squeezed using flat forceps to obtain the entrapped serum as documented elsewhere $[4,14]$. Freshly isolated hyperacute sera were pooled and stored at $-20^{\circ} \mathrm{C}$. Lyophilized HAS (hypACT, OrthoSera Kft) was prepared from pooled freshly isolated HAS that was filtered with an IgM antibodies BioScale Mini 
CHT ceramic hydroxyapatite cartridge type II (BioRad, 7324332). Afterwards, $2 \mathrm{~mL}$ of pooled sterile serum per vial were frozen at $-20{ }^{\circ} \mathrm{C}$ for $30 \mathrm{~min}$, and afterwards, cooled with liquid nitrogen for $10 \mathrm{~min}$. Finally, it was freeze dried to produce the lyophilized powder with Labcondo Triad (Fisher Scientific, 794001030). Non-filtered lyophilized HAS (hypACT, OrthoSera Kft) followed the same protocol, excluding the filtration step with the IgM column. Both formulations of lyophilized HAS were stored at room temperature.

\subsection{Viability Assay of $2 D$ Chondrogenic Cultures}

$2 \times 10^{3}$ primary isolated chondrocytes per well were seeded in 96-well plates and kept in culture medium (see above) for $48 \mathrm{~h}$. Then, medium was exchanged for different supplemented media and the XTT assay Cell Proliferation kit II (Roche Diagnostics, 11465015001) was performed in triplicates at days $0,3,5$ and 7 . All conditions were prepared from a basal combination of serum-free DMEM medium, Pen/Strep, AmphoB and ascorbic acid as previously described. Then, media were completed as follows: $+10 \%$ blood-derived product (different formulations of HAS or PRP) $+10 \%$ FCS, $10 \%$ FCS $+2 \%$ hyaluronic acid (HA) Monovisc (Anika Therapeutics, 690008), or $+10 \%$ HAS $+2 \%$ HA. Medium was exchanged at day 4 .

\subsection{RNA Isolation and Quantitative Real-Time PCR ( $q R T-P C R$ )}

A total of $6 \times 10^{4}$ primary isolated chondrocytes per well were seeded in six-well plates and different supplemented media were added (see media conditions above). Total RNA isolation was performed at days 0,3 and 7 with the High Purity RNA isolation kit (Roche Diagnostics, \#11828665001) together with DNAse I (Thermo Scientific, EN0521). Isolated RNA was reverse transcribed with the Transcriptor cDNA synth kit (Roche Diagnostics, 4897030001). For the RT-qPCR quantification, the FastStart Essential DNA Probes Master (Roche Diagnostics, 6402682001) was used. The following genes were analyzed: Gapdh, Acan, Col2a1, Col1a1, Sox9, Mmp-3, Mmp-13 and Prg4. Sequences of primers and probes $\left(3^{\prime}-5^{\prime}\right)$ can be found in Table 4 . Medium was changed at day 4 .

Table 4. List of sequences for primers and probes used during gene expression analysis $\left(3^{\prime}-5^{\prime}\right)$.

\begin{tabular}{cccc}
\hline Gene & Forward Primer & Reverse Primer & Probe \\
\hline Gapdh & ATGTTCCAGTATGATTCCACCC & ATACTCAGCACCAGCATCAC & AGCTTCCCGTTCTCTGCCTTGAC \\
\hline Acan & ACCTACGATGTCTACTGCTACG & AGAGTGGCGTTTTGGGATTC & AGAAGGTGAACTGCTCCAGGCG \\
\hline Col2a1 & GTGCAACTGGTCCTCTGG & ACCTCTTTTCCCTTCTTCACC & CCTTGTTCGCCTTTGAAGCCAGC \\
\hline Col1a1 & CCCCTGGAAAGAATGGAGATG & TCCAAACCACTGAAACCTCTG & TTCCGGGCAATCCTCGAGCA \\
\hline Sox 9 & ACTTGCACAACGCCGAG & CTGGTACTTGTAATCCGGGTG & TCTGGAGACTTCTGAACGAGAGCGA \\
\hline$M m p-3$ & CCAGGGATTAATGGAGATGCC & AGTGTTGGCTGAGTGAAAGAG & ACAATGGACAAAGGATACAACAGGGACC \\
\hline$M m p-13$ & CTAAACATCCCAAAACGCCAG & ACAGCTCTGCTTCAACCTG & CCCTTGATGCCATAACCAGTCTCCG \\
\hline$P r g 4$ & AGAACTGGCCTGAATCTGTG & ACCTGTGTCGTTTCTCCATAC & TCAAGAGAGGTGGCAGCATTCAGC \\
\hline
\end{tabular}

\subsection{Explant Co-Culture for the Inflammatory Model}

Synovial, bone and articular cartilage tissues from human OA samples were identified and minced as explained elsewhere [19]. Five fragments of cartilage, four of bone and two to three of synovium, depending on availability, were placed per well to establish a co-culture. Culture medium was supplemented with $10 \mathrm{ng} / \mathrm{mL}$ of IL-1 $\beta$ (Shenandoah, 100$167 \mathrm{AF}$ ) for $48 \mathrm{~h}$. Then, the inflammatory medium was replaced by different cultured media for 5 days, with medium exchange at day 4 . Cultured medium included the following conditions: 10\% FCS, 10\% FCS + 2\% HA, 10\% non-filtered lyophilized HAS, 10\% nonfiltered lyophilized HAS $+2 \%$ HA (Scheme 1). Supernatant fluids were collected at days 0 , 3 and 5 and proteins were quantified with the Bio-Plex Pro Human Cytokine 27-plex Assay (BioRad, M500KCAF0Y). 


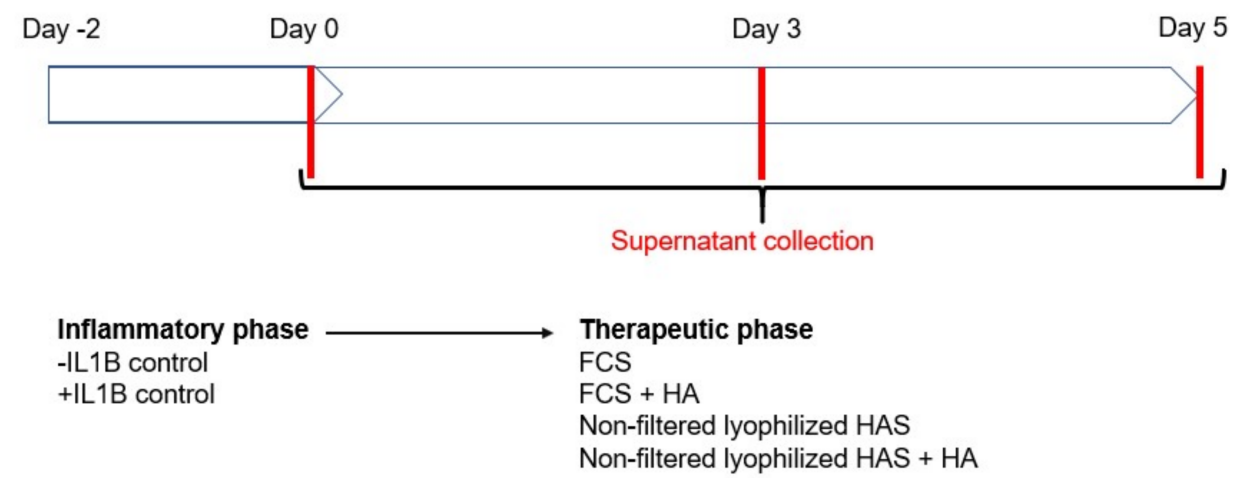

Scheme 1. Experimental design of the inflammatory co-culture model experiment. The schematic represents the timeline and the conditioning medium that was used in each phase. Abbreviations: fetal calf serum (FCS), hyperacute serum (HAS), hyaluronic acid (HA), interleukin 1 beta (IL-1 $\beta$ ).

\subsection{Statistical Analysis}

GraphPad Prism software (version 7, GraphPad Prism software Inc (Irvine, CA, USA) was used to perform the statistics of this study, where $p<0.05$ was accepted to determine a statistical significance. For the XTT analysis included in Figure 1, linear regression comparisons were performed. RT-qPCR and XTT data included in Figures 2 and 3 were analyzed via one-way ANOVA test corrected with Tukey's multiple comparison test. Protein quantifications were analyzed by using one-way ANOVA with Benjamini, Krieger and Yekutieli post-correction for Gaussian distributed samples or Friedman test for nonparametric samples, corrected with Dunn's multiple comparison test. Pearson correlations were performed and considered strong when $r>0.75$. Graphs represent arithmetic mean values \pm SD. $p$-values are represented as follows: $<0.05\left(^{*}\right)$ and $<0.01\left({ }^{* *}\right)$.

Supplementary Materials: The following are available online at https:/ / www.mdpi.com/article/ 10.3390/ijms22147496/s1, Table S1: List of Pearson correlation values for the different conditions, Table S2: List of Pearson correlation values for the different conditions.

Author Contributions: Conceptualization, O.K.-P.; methodology, I.O.C., O.K.-P., A.D.L., K.K. and D.K.; validation, I.O.C. and O.K.-P.; formal analysis, I.O.C. and O.K.-P.; investigation, I.O.C. and K.K.; resources, Á.M., S.T., D.S., S.E.-B., T.B., Z.L. and S.N.; data curation, I.O.C.; writing-original draft preparation, I.O.C.; writing-review and editing, O.K.-P.; visualization, I.O.C.; supervision, Z.L., O.K.-P. and S.N.; project administration, I.O.C. and A.D.L.; funding acquisition, O.K.-P. and A.D.L. All authors have read and agreed to the published version of the manuscript.

Funding: This research was funded by the Fund for Economy and Tourism of Lower Austria, grant number WST3-F-5030664/015-2019.

Institutional Review Board Statement: The study approval by the Ethics Committee from NiederOesterreich (GS4-EK-4/674-2020) on the 17 November 2020.

Informed Consent Statement: Informed consent was obtained from all subjects involved in the study.

Data Availability Statement: The data presented in this study are openly available in FigShare, doi:10.6084/m9.figshare.14973663.

Acknowledgments: The authors are thankful to OrthoSera GmbH for providing hyperacute sera and to the research support of University of Pécs (Hungary) and Danube University in Krems (Austria).

Conflicts of Interest: O.K.-P., A.M., S.T. and I.O.C. are employees and Z.L. is the scientific founder of OrthoSera $\mathrm{GmbH}$, a startup company developing hyperacute serum technology towards clinical applications.

\section{References}

1. Zhang, Y.; Jordan, J.M. Epidemiology of osteoarthritis. Clin. Geriatr. Med. 2010, 26, 355-369. [CrossRef] [PubMed]

2. Zhang, W.; Nuki, G.; Moskowitz, R.; Abramson, S.; Altman, R.; Arden, N.; Bierma-Zeinstra, S.; Brandt, K.; Croft, P.; Doherty, M.; et al. OARSI recommendations for the management of hip and knee osteoarthritis: Part III: Changes in evidence following systematic cumulative update of research published through January 2009. Osteoarthr. Cartil. 2010, 18, 476-499. [CrossRef] 
3. Bielecki, T.; Dohan Ehrenfest, D.M. Platelet-rich plasma (PRP) and platelet-rich fibrin (PRF): Surgical adjuvants, preparations for in situ regenerative medicine and tools for tissue engineering. Curr. Pharm. Biotechnol. 2012, 13, 1121-1130. [CrossRef] [PubMed]

4. Kardos, D.; Simon, M.; Vácz, G.; Hinsenkamp, A.; Holczer, T.; Cseh, D.; Sárközi, A.; Szenthe, K.; Bánáti, F.; Szathmary, S.; et al. The composition of hyperacute serum and plate-let-rich plasma is markedly different despite the similar production method. Int. J. Mol. Sci. 2019, 20, 721. [CrossRef] [PubMed]

5. Taniguchi, Y.; Yoshioka, T.; Kanamori, A.; Aoto, K.; Sugaya, H.; Yamazaki, M. Intra-articular platelet-rich plasma (PRP) injections for treating knee pain associated with osteoarthritis of the knee in the Japanese population: A phase I and IIa clinical trial. Nagoya J. Med. Sci. 2018, 80, 39-51. [CrossRef]

6. Meheux, C.J.; McCulloch, P.; Lintner, D.M.; Varner, K.E.; Harris, J.D. Efficacy of intra-articular platelet-rich plasma injections in knee osteoarthritis: A systematic review. Arthrosc. J. Arthrosc. Relat. Surg. 2016, 32, 495-505. [CrossRef]

7. Di Martino, A.; Di Matteo, B.; Papio, T.; Tentoni, F.; Selleri, F.; Cenacchi, A.; Kon, E.; Filardo, G. Platelet-rich plasma versus hyaluronic acid injections for the treatment of knee osteoarthritis: Results at 5 years of a double-blind, randomized controlled trial. Am. J. Sports Med. 2019, 47, 347-354. [CrossRef]

8. Tuakli-Wosornu, Y.A.; Terry, A.; Boachie-Adjei, K.; Harrison, J.R.; Gribbin, C.K.; LaSalle, E.E.; Nguyen, J.T.; Solomon, J.L.; Lutz, G.E. Lumbar intradiskal platelet-rich plasma (PRP) injections: A prospective, double-blind, randomized controlled study. PMR 2016, 8, 1-10. [CrossRef] [PubMed]

9. Andia, I.; Perez-Valle, A.; Del Amo, C.; Maffulli, N. Freeze-drying of platelet-rich plasma: The quest for standardization. Int. J. Mol. Sci. 2020, 21, 6904. [CrossRef] [PubMed]

10. Dohan Ehrenfest, D.M.; Andia, I.; Zumstein, M.A.; Zhang, C.Q.; Pinto, N.R.; Bielecki, T. Classification of platelet concentrates (platelet-rich plasma-PRP, platelet-rich fibrin-PRF) for topical and infiltrative use in orthopedic and sports medicine: Current consensus, clinical implications and perspectives. Muscles Ligaments Tendons J. 2014, 4, 3-9. [CrossRef]

11. Fernández-Barbero, J.E.; Galindo-Moreno, P.; Ávila-Ortiz, G.; Caba, O.; Sánchez-Fernández, E.; Wang, H.L. Flow cytometric and morphological characterization of platelet-rich plasma gel. Clin. Oral Implant. Res. 2006, 17, 687-693. [CrossRef] [PubMed]

12. Jensen, T.; Kierulf, P.; Sandset, P.M.; Klingenberg, O.; Joø, G.B.; Godal, H.C.; Skjønsberg, O.H. Fibrinogen and fibrin induce synthesis of pro-inflammatory cytokines from isolated peripheral blood mononuclear cells. Thromb. Haemost. 2007, 97, 822-829. [PubMed]

13. Zhou, Y.; Zhang, J.; Wu, H.; Hogan, M.V.; Wang, J.H.-C. The differential effects of leukocyte-containing and pure platelet-rich plasma (PRP) on tendon stem/progenitor cells-Implications of PRP application for the clinical treatment of tendon injuries. Stem Cell Res. Ther. 2015, 6, 1-13. [CrossRef]

14. Vácz, G.; Major, B.; Gaál, D.; Petrik, L.; Horváthy, D.B.; Han, W.; Holczer, T.; Simon, M.; Muir, J.M.; Hornyák, I.; et al. Hyperacute serum has markedly better regenerative efficacy than platelet-rich plasma in a human bone oxygen-glucose deprivation model. Regen. Med. 2018, 13, 531-543. [CrossRef]

15. Kuten, O.; Simon, M.; Hornyák, I.; De Luna-Preitschopf, A.; Nehrer, S.; Lacza, Z. The effects of hyperacute serum on adipo-genesis and cell proliferation of mesenchymal stromal cells. Tissue Eng. Part. A 2018, 24, 1011-1021. [CrossRef] [PubMed]

16. Jeyakumar, V.; Niculescu-Morzsa, E.; Bauer, C.; Lacza, Z.; Nehrer, S. Platelet-rich plasma supports proliferation and redifferentiation of chondrocytes during in vitro expansion. Front. Bioeng. Biotechnol. 2017, 5, 1-8. [CrossRef]

17. Simon, M.; Major, B.; Vácz, G.; Kuten, O.; Hornyak, I.; Hinsenkamp, A.; Kardos, D.; Bagó, M.; Cseh, D.; Sarkozi, A.; et al. The effects of hyperacute serum on the elements of the human subchondral bone marrow niche. Stem Cells Int. 2018, $2018,1-12$. [CrossRef]

18. Neubauer, M.; Kuten, O.; Stotter, C.; Kramer, K.; De Luna, A.; Muellner, T.; Lacza, Z.; Nehrer, S. The effect of blood-derived products on the chondrogenic and osteogenic differentiation potential of adipose-derived mesenchymal stem cells originated from three different locations. Stem Cells Int. 2019, 2019, 1-20. [CrossRef]

19. Kardos, D.; Marschall, B.; Simon, M.; Hornyák, I.; Hinsenkamp, A.; Kuten, O.; Gyevnár, Z.; Erdélyi, G.; Bárdos, T.; Paukovits, T.M.; et al. Investigation of cytokine changes in osteo-arthritic knee joint tissues in response to hyperacute serum treatment. Cells 2019, 8, 824. [CrossRef] [PubMed]

20. Johnson, C.I.; Argyle, D.J.; Clements, D.N. In vitro models for the study of osteoarthritis. Veter. J. 2016, 209, 40-49. [CrossRef]

21. Man, G.S.; Mologhianu, G. Osteoarthritis pathogenesis-A complex process that involves the entire joint. J. Med. Life 2014, 7, 37-41.

22. Otero, M. In vitro OA models to study chondrocytes and cartilage. Osteoarthr. Cartil. 2018, 26, S4-S5. [CrossRef]

23. Jayadev, C.; Snelling, S.; Price, A.J.; Hulley, P.A. Multiplex analysis of osteoarthritic synovial fluid: A comparison of Luminex \& Mesoscale discovery. Osteoarthr. Cartil. 2013, 21, S73. [CrossRef]

24. Mabey, T.; Honsawek, S. Cytokines as biochemical markers for knee osteoarthritis. World J. Orthop. 2015, 6, 95-105. [CrossRef] [PubMed]

25. Daghestani, H.; Kraus, V. Inflammatory biomarkers in osteoarthritis. Osteoarthr. Cartil. 2015, 23, 1890-1896. [CrossRef]

26. Wojdasiewicz, P.; Poniatowski, Ł.A.; Szukiewicz, D. The role of inflammatory and anti-inflammatory cytokines in the pathogenesis of osteoarthritis. Mediat. Inflamm. 2014, 2014, 1-19. [CrossRef]

27. Maldonado, M.; Nam, J. The role of changes in extracellular matrix of cartilage in the presence of inflammation on the pathology of osteoarthritis. BioMed Res. Int. 2013, 2013, 284873. [CrossRef] [PubMed]

28. Baheti, A.; Kumar, L.; Bansal, A.K. Excipients used in lyophilization of small molecules. J. Excip. Food Chem. 2010, 1, 41-54. 
29. Butreddy, A.; Dudhipala, N.; Janga, K.Y.; Gaddam, R.P. Lyophilization of small-molecule injectables: An industry perspective on formulation development, process optimization, scale-up challenges, and drug product quality attributes. AAPS PharmSciTech 2020, 21, 251-271. [CrossRef]

30. Goa, K.L.; Benfield, P. Hyaluronic acid: A review of its pharmacology and use as a surgical aid in ophthalmology, and its therapeutic potential in joint disease and wound healing. Drugs 1994, 47, 536-566. [CrossRef]

31. Raeissadat, S.A.; Rayegani, S.M.; Hassanabadi, H.; Fathi, M.; Ghorbani, E.; Babaee, M.; Azma, K. Knee osteoarthritis injection choices: Platelet- rich plasma (PRP) versus hyaluronic acid (a one-year randomized clinical trial). Clin. Med. Insights Arthritis Musculoskelet. Disord. 2015, 8, 1-8. [CrossRef]

32. Andía, I.; Abate, M. Knee osteoarthritis: Hyaluronic acid, platelet-rich plasma or both in association? Expert Opin. Biol. Ther. 2014, 14, 635-649. [CrossRef]

33. Hayes, A.J.; Melrose, J. Glycosaminoglycan and proteoglycan biotherapeutics in articular cartilage protection and repair strategies: Novel approaches to visco-supplementation in orthobiologics. Adv. Ther. 2019, 2, 1900034. [CrossRef]

34. Chen, X.; Sadineni, V.; Maity, M.; Quan, Y.; Enterline, M.; Mantri, R.V. Finite Element Method (FEM) modeling of freeze-drying: Monitoring pharmaceutical product robustness during lyophilization. AAPS PharmSciTech 2015, 16, 1317-1326. [CrossRef] [PubMed]

35. Wolkers, W.F.; Oldenhof, H. Cryopreservation and Freeze-Drying Protocols; Springer: New York, NY, USA, 2021.

36. Kasper, J.C.; Friess, W. The freezing step in lyophilization: Physico-chemical fundamentals, freezing methods and consequences on process performance and quality attributes of biopharmaceuticals. Eur. J. Pharm. Biopharm. 2011, 78, 248-263. [CrossRef]

37. Fissore, D.; Pisano, R.; Barresi, A.A. Process analytical technology for monitoring pharmaceuticals freeze-drying-A comprehensive review. Dry. Technol. 2018, 36, 1839-1865. [CrossRef]

38. Akeda, K.; An, H.; Okuma, M.; Attawia, M.; Miyamoto, K.; Thonar, E.-M.; Lenz, M.; Sah, R.; Masuda, K. Platelet-rich plasma stimulates porcine articular chondrocyte proliferation and matrix biosynthesis. Osteoarthr. Cartil. 2006, 14, 1272-1280. [CrossRef]

39. Spreafico, A.; Chellini, F.; Frediani, B.; Bernardini, G.; Niccolini, S.; Serchi, T.; Collodel, G.; Paffetti, A.; Fossombroni, V.; Galeazzi, M.; et al. Biochemical investigation of the effects of human platelet releasates on human articular chondrocytes. J. Cell. Biochem. 2009, 108, 1153-1165. [CrossRef]

40. Drengk, A.; Zapf, A.; Stürmer, E.K.; Stürmer, K.M.; Frosch, K.-H. Influence of platelet-rich plasma on chondrogenic differentiation and proliferation of chondrocytes and mesenchymal stem cells. Cells Tissues Organs 2009, 189, 317-326. [CrossRef]

41. Russo, F.; D’Este, M.; Vadalà, G.; Cattani, C.; Papalia, R.; Alini, M.; Denaro, V. Platelet rich plasma and hyaluronic acid blend for the treatment of osteoarthritis: Rheological and biological evaluation. PLoS ONE 2016, 11, e0157048. [CrossRef]

42. Chen, W.-H.; Lo, W.-C.; Hsu, W.-C.; Wei, H.-J.; Liu, H.-Y.; Lee, C.-H.; Chen, S.-Y.T.; Shieh, Y.-H.; Williams, D.F.; Deng, W.-P. Synergistic anabolic actions of hyaluronic acid and platelet-rich plasma on cartilage regeneration in osteoarthritis therapy. Biomaterials 2014, 35, 9599-9607. [CrossRef]

43. Smyth, N.A.; Ross, K.; Haleem, A.M.; Hannon, C.P.; Murawski, C.D.; Do, H.T.; Kennedy, J.G. Platelet-rich plasma and hyaluronic acid are not synergistic when used as biological adjuncts with autologous osteochondral transplantation. Cartilage 2016, 9, 321-328. [CrossRef]

44. Melrose, J. The Importance of the knee joint meniscal fibrocartilages as stabilizing weight bearing structures providing global protection to human knee-joint tissues. Cells 2019, 8, 324. [CrossRef] [PubMed]

45. Melrose, J.; Fuller, E.S.; Little, C.B. The biology of meniscal pathology in osteoarthritis and its contribution to joint disease: Beyond simple mechanics. Connect. Tissue Res. 2017, 58, 282-294. [CrossRef]

46. Chabane, N.; Zayed, N.; Afif, H.; Mfuna-Endam, L.; Benderdour, M.; Boileau, C.; Martel-Pelletier, J.; Duval, N.; Fahmi, H. Histone deacetylase inhibitors suppress interleukin-1 $\beta$-induced nitric oxide and prostaglandin E2 production in human chondrocytes. Osteoarthr. Cartil. 2008, 16, 1267-1274. [CrossRef]

47. Ying, X.; Chen, X.; Cheng, S.; Shen, Y.; Peng, L.; Xu, H.Z. Piperine inhibits IL- $\beta$ induced expression of inflammatory mediators in human osteoarthritis chondrocyte. Int. Immunopharmacol. 2013, 17, 293-299. [CrossRef] [PubMed]

48. Kobayashi, M.; Squires, G.R.; Mousa, A.; Tanzer, M.; Zukor, D.J.; Antoniou, J.; Feige, U.; Poole, A.R. Role of interleukin-1 and tumor necrosis factor $\alpha$ in matrix degradation of human osteoarthritic cartilage. Arthritis Rheum. 2005, 52, 128-135. [CrossRef] [PubMed]

49. Thomas Vangsness, J.; Burke, W.S.; Narvy, S.J.; MacPhee, R.D.; Fedenko, A.N. Human knee synovial fluid cytokines correlated with grade of knee osteoarthritis: A pilot study. Bull. NYU Hosp. Jt. Dis. 2011, 69, 122-127.

50. Vernal, R.; Velásquez, E.; Gamonal, J.; Garcia-Sanz, J.A.; Silva, A.; Sanz, M. Expression of proinflammatory cytokines in osteo-arthritis of the temporomandibular joint. Arch. Oral Biol. 2008, 53, 910-915. [CrossRef]

51. Miller, R.E.; Miller, R.J.; Malfait, A.-M. Osteoarthritis joint pain: The cytokine connection. Cytokine 2014, 70, 185-193. [CrossRef] [PubMed]

52. Lee, K.-C.; Prasad, V.; Achuthan, A.; Fleetwood, A.; Hamilton, J.; Cook, A. Targeting GM-CSF for collagenase-induced osteoarthritis pain and disease in mice. Osteoarthr. Cartil. 2020, 28, 486-491. [CrossRef] [PubMed]

53. Bykerk, V.P. The efficacy and safety of targeting GM-CSF in arthritis. Lancet Rheumatol. 2020, 2, e648-e650. [CrossRef]

54. Chen, Z.; Ma, Y.; Li, X.; Deng, Z.; Zheng, M.; Zheng, Q. The immune cell landscape in different anatomical structures of knee in osteoarthritis: A gene expression-based study. BioMed Res. Int. 2020, 2020, 9647072. [CrossRef] [PubMed] 
55. Armah, H.B.; Wilson, N.O.; Sarfo, B.Y.; Powell, M.D.; Bond, V.C.; Anderson, W.; Adjei, A.A.; Gyasi, R.K.; Tettey, Y.; Wiredu, E.K.; et al. Cerebrospinal fluid and serum biomarkers of cerebral malaria mortality in Ghanaian children. Malar. J. 2007, 6, 147. [CrossRef]

56. de-Oliveira-Pinto, L.M.; Gandini, M.; Freitas, L.P.; Siqueira, M.M.; Marinho, C.F.; Setúbal, S.; Kubelka, C.F.; Cruz, O.G.; de Oliviera, S.A. Profile of circulating levels of IL-1Ra, CXCL10/IP-10, CCL4/MIP-1 $\beta$ and CCL2/MCP-1 in dengue fever and parvovirosis. Mem Inst. Oswaldo Cruz. 2012, 107, 48-56. [CrossRef]

57. Ren, G.; Lutz, I.; Railton, P.; Wiley, J.P.; McAllister, J.; Powell, J.; Krawetz, R.J.; Railton, P.; Wiley, J.P.; McAllister, P.; et al. Serum and synovial fluid cytokine profiling in hip osteo-arthritis: Distinct from knee osteoarthritis and correlated with pain. BMC Musculoskelet Disord. 2018, 19, 1-11. [CrossRef]

58. Nees, T.A.; Rosshirt, N.; Zhang, J.A.; Reiner, T.; Sorbi, R.; Tripel, E.; Walker, T.; Schiltenwolf, M.; Hagmann, S.; Moradi, B. Synovial cytokines significantly correlate with osteoar-thritis-related knee pain and disability: Inflammatory mediators of potential clinical relevance. J. Clin. Med. 2019, 8, 1343. [CrossRef] [PubMed] 